\title{
Global Incidence and Mortality Rate of COVID-19; Special Focus on Iran, Italy and China
}

\author{
Samira Chaibakhsh, $\mathrm{PhD}^{1,2}$, Asma Pourhoseingholi, $\mathrm{PhD}^{3^{*}}$, Mohsen Vahedi, $\mathrm{PhD}^{4}$ \\ 'Eye Research Center, The Five Senses Institute, Rassoul Akram Hospital, Iran University of Medical Sciences, Tehran, Iran \\ ${ }^{2}$ Neuromusculoskeletal Research Center, Iran University of Medical Sciences, Tehran, Iran \\ ${ }^{3}$ Department of Biostatistics, Faculty of Paramedical Sciences, Shahid Beheshti University of Medical Sciences, Tehran, Iran \\ ${ }^{4}$ Department of Biostatistics, University of Social Welfare and Rehabilitation Sciences, Tehran, Iran
}

\begin{abstract}
Background: Severe acute respiratory syndrome coronavirus 2 (SARS-CoV-2), a new coronavirus, was diagnosed in China in December 2019. Around the globe, a total of 71429 were infected up to February 17, 2020, with 98.9\% of cases in China. On March 11, 2020, the World Health Organization (WHO) characterized the COVID-19 as 'pandemic'. Rapid positive worldwide incidence was the motivation behind this study to investigate the incidence and mortality globally.

Methods: We used the data published by the WHO until March 9, 2020. Non-parametric tests and change point analysis were used for inferences.

Results: Change point analysis for Iran and China and the world excluding China for the first 20 days revealed around 78, 195 and 2 further new cases per day, respectively. Italy had a big jump in incidence on the $36^{\text {th }}$ day. Similarly, a sharp rise of positive cases was reported for the world on the $35^{\text {th }}$ day. China successfully controlled the ascending reports of incidence on the $23^{\text {rd }}$ day. Mortality in China and the world were almost similar for the first 20 days. There was an ascending incidence trend with two change points in Italy $\left(30^{\text {th }}\right.$ and $36^{\text {th }}$ days) and one change point in Iran on the $17^{\text {th }}$ day. Mortality in the world jumped remarkably after day 42 with an estimation of almost more than 25 deaths per day.

Conclusion: The incidence of COVID-19 varied by regions; however, after March 11, it became 'pandemic'. It was observed that after about 6 days with an emergence of sharp increase in incidences, there would be a mutation in mortality rate. On the other hand, the importance of 'on-time' quarantine programs in controlling this virus was confirmed.

Keywords: COVID-19, Incidence, Mortality

Cite this article as: Chaibakhsh S, Pourhoseingholi A, Vahedi M. Global incidence and mortality rate of COVID-19; special focus on Iran, Italy and China. Arch Iran Med. 2020;23(7):455-461. doi: 10.34172/aim.2020.42.
\end{abstract}

Received: March 20, 2020, Accepted: April 2, 2020, ePublished: July 1, 2020

\section{Introduction}

Severe acute respiratory syndrome coronavirus 2 (SARSCoV-2), a new coronavirus, was diagnosed in Wuhan, Hubei province, China, in December 2019. ${ }^{1}$ This novel virus rapidly spread to all provinces of China and 25 countries in the Asia-Pacific Region, North America, Europe, and South America within 1 month of its discovery. ${ }^{2}$

The origin of SARS-CoV-2 is assumed to be from bats; it moved to intermediate hosts before transmitting to humans, resulting in a pneumonia which is similar to the other coronaviruses such as the SARS-CoV and the Middle East Respiratory Syndrome-associated coronavirus (MERS-CoV). ${ }^{3-5}$

Although the International Committee on Taxonomy of Viruses (ICTV) classified this novel virus as SARS-CoV-2, on February 11, 2020, this novel virus was renamed as the 'coronavirus disease 2019' (COVID-19) by the World Health Organization (WHO). Worldwide, a total of 71 429 were infected as of February 17, 2020 with 70635
(98.9\%) cases occurring in China. Also, 1772 deaths were reported in China with a crude mortality of $2.5 \%{ }^{6}$ Finally, on March 11, 2020, the WHO characterized the COVID-19 as pandemic. ${ }^{7}$

The first report of outbreak in Iran was on February $20 .^{8}$ Qom, a city in central Iran near the capital Tehran (the distance between Qom and Tehran is $148 \mathrm{~km}$ and about 92 miles), was considered as the first place for the outbreak of COVID-19 in Iran. The infection rapidly disseminated to all provinces of Iran within 15 days.

A similar situation as Iran occurred in Italy, which is in Europe. The first case of COVID-19 was reported on January $13,{ }^{9}$ and the rapid spread of contagion in Italy after February 21 was considerable. Iran and Italy faced with an unexpected situation with rapid spread of contagion.

In this study, we aimed to conduct a global comparison according to incidence and mortality rates and identifying the dates with considerable mutation in the trend of incidence and mortality rates. Similarly, due to the large outbreak in Iran and Italy, we aimed to make a comparison 
between China, Iran and Italy and the world according to incidence rate and mortality rates until March 9, 2020.

\section{Material and Methods}

Data Source

We used the data that was collected and disseminated by the WHO about the coronavirus regarding confirmed, recovered, and death cases. The data reported from January 22, 2020 is updated daily and available on the RamiKrispin dataset. $^{10}$

Cumulative Incidence and Mortality Rate until March 9, 2020

For the global comparison of incidence rate and mortality rate, we divided the world into five regions according to the WHO. ${ }^{2}$ We excluded China as it was the origin of the virus and an outlier.

Incidence and mortality rate of the five regions were compared. Also, the relationship between Human Development Index (HDI) and incidence and mortality rate were measured. HDI is a statistic composite index of life expectancy, education, and per capita income indicators, which are used to rank countries based on human development. A country scores a higher HDI when the lifespan, education level and gross national income per capita are higher. ${ }^{11}$

\section{Trend Analysis}

The global trend of incidence, mortality rate and the critical days with an increase or decrease in trend were identified. The same process was performed to assess the trend of incidence and mortality rate in Italy and China. In order to obtain further information, the data pertaining to China was omitted from the global data and the analysis was repeated.

Another comparison was made using the data of the first 20 days from global reports, China and Iran. Truncating the other information made it possible to compare the trend between Iran and China and the world - the 20 days for Iran were reported until March 9.

Statistical Analysis

The relationship between continuous data was assessed using Spearman correlation. To compare the incidence and mortality rates, the Kruskal-Wallis test was used. Trends analysis were performed using change point analysis. 'Change-point analysis' is a technique to assess the critical and multiple change-points over the long-term population and health trends. The term 'change-point' describes the time at which a change began to occur. However, in long period data, we can have more clear pattern and time shifts. ${ }^{12}$ All analyses were performed using the SPSS 22 and Joinpoint software. $P$ values $<0.05$ were considered significant.

\section{Results}

A total of 63 countries were included in the study. Countries with fewer than two reported cases and incomplete death information were omitted. The highest incidence and mortality rates after China pertained to San Marino and the Philippines, respectively, and the lowest ranks belonged to Indonesia and the Netherlands, respectively.

\section{Global Overview of COVID-19 Incidence and Mortality Rates}

As mentioned before, the whole world was divided into five regions. Then, the incidence and mortality rates were compared according to these five regions. The lowest and highest mortality rates were observed in the European region and the Western Pacific Region, respectively. Likewise, the lowest and highest incidence rates were reported from the European region and Africa, respectively. Comparison according to incidence showed a significant statistical difference $(P$ value $=0.015)$. Accordingly, on 'two by two' comparison, the incidence in the European region vs. the African region (44.17 per 1000000 vs. 0.25 per $1000000, P$ value $=0.025)$, the European region vs. the Americas (44.17 per 1000000 vs. 0.67 per 1,000,000, $P$ value $=0.008)$ and the European region vs. the South-East Asian region (44.17 per 1000000 vs. 1.36 per 1000000 , $P$ value $=0.035)$ were statistically different $($ Table 1$)$.

The HDI of each country was used according to the WHO reports. Incidence differed significantly between countries with different HDI ( $\mathrm{r}=0.70, P$ value $\leq 0.001)$; with increasing HDI, incidence was raised. However, we did not find any significant correlation between this index

Table 1. Global Overview of Incidence and Mortality Rate

\begin{tabular}{|c|c|c|c|c|c|c|c|c|c|}
\hline \multirow{2}{*}{ Region } & \multicolumn{3}{|c|}{ Incidence Per 1000000} & \multirow[b]{2}{*}{ SD } & \multirow{2}{*}{$P$ Value } & \multicolumn{2}{|c|}{ Mortality Rate Per 1000000} & \multirow[b]{2}{*}{ SD } & \multirow{2}{*}{$P$ Value } \\
\hline & $n$ & Mean & $\mathrm{Cl}$ & & & Mean & $\mathrm{Cl}$ & & \\
\hline Africa & 2 & 0.25 & $(0-0.58)$ & 0.24 & \multirow{6}{*}{0.015} & 0.00 & - & 0.00 & \multirow{6}{*}{0.781} \\
\hline Eastern Mediterranean & 13 & 11.06 & $(0-40.76)$ & 21.43 & & 1.24 & $(0-2.68)$ & 2.64 & \\
\hline European & 28 & 44.17 & $(0-101.46)$ & 154.68 & & 0.45 & $(0.06-0.84)$ & 1.04 & \\
\hline Region of the Americas & 5 & 0.67 & $(0-1.19)$ & 0.59 & & 1.03 & $(0-3.05)$ & 2.31 & \\
\hline South-East Asia & 4 & 1.36 & $(0-3.55)$ & 2.23 & & 0.50 & $(0-1.48)$ & 1.00 & \\
\hline Western Pacific & 9 & 35.21 & $(0-95.69)$ & 92.57 & & 2.53 & $(0-6.1)$ & 5.47 & \\
\hline
\end{tabular}


and mortality rate $(\mathrm{r}=0.11, P$ value $=0.403)$.

Trend of Incidence and Change Points over Time Trend of Incidence in China, Italy and Globally

The first COVID-19 case was reported in China on January 22, 2020. The first reports from Italy and Iran came on January 31, and February 20, respectively. However, the information of only two days was reported from Italy during the first 20 days.

First, based on the global analysis, there was a significant global trend $(P$ value $<0.001)$ during the first 14 days, estimating 315 further new cases every. From the $15^{\text {th }}$ to $35^{\text {th }}$ day, the number of new cases per day was significantly lower compared with the previous day $(P$ value $<0.001)$. New cases per each day decreased by about 148 compared to the previous day. Then on the $36^{\text {th }}$ day, a significant increase occurred again $(P$ value $<0.001)$ although the new cases in each day were lower compared to the first 20 days (about 227 further new cases each day) (Figure 1A).

The trend of incidence in China, like the rest of the globe, increased significantly $(P$ value $<0.001)$. However new cases added were lower compared to the previous day (about 150 cases). Then, for the rest of the days, there was a significant descending slope $(P$ value $<0.001)$ with an estimation of -207 (Figure 1B). In other words, on average, the new cases would diminish by 207 compared to new cases of every previous day. In the next step of our analysis, China, as an outlier, was omitted from the global analysis and the results showed only one change point. Although a significant increasing trend was detected, the number of further new cases reported every day was about 8 during the first 35 days which then increased to about 303 (both $P$ value $<0.001)$. As for Italy, we analyzed from the first day of the outbreak until April 9 due to lack of data for the first 20 days in Italy. Italy had a statistically significant ascending slope but with two change points. During the first 27 days, no significant trend was detected, but on the $28^{\text {th }}$ day, there was a change point which showed a significant positive trend. The results showed that each day, about 63 new cases would be added ( $P$ value $<0001$ ). A remarkable change occurred on the $36^{\text {th }}$ day which showed a large outbreak. An ascending trend ensued with a steeper slope $(P$ value $<0.001)$ compared to the previous days. The estimation showed that on average, 286 new cases would be added every day to the previous new cases (Figure 1C).

Comparing Incidence Trend in the First 20 Days in China, Iran and Globally

In the first 7 days of the outbreak in Iran, there was no significant trend but from the 8th day, a significant ascending trend occurred $(P$ value $<0.001)$. The estimated slope showed that about 78 new cases would be added per day (Figure 1D). The change point analysis showed a positive significant trend with a no change point in China (195 further cases per day, $P$ value $<0.001)$ and the world
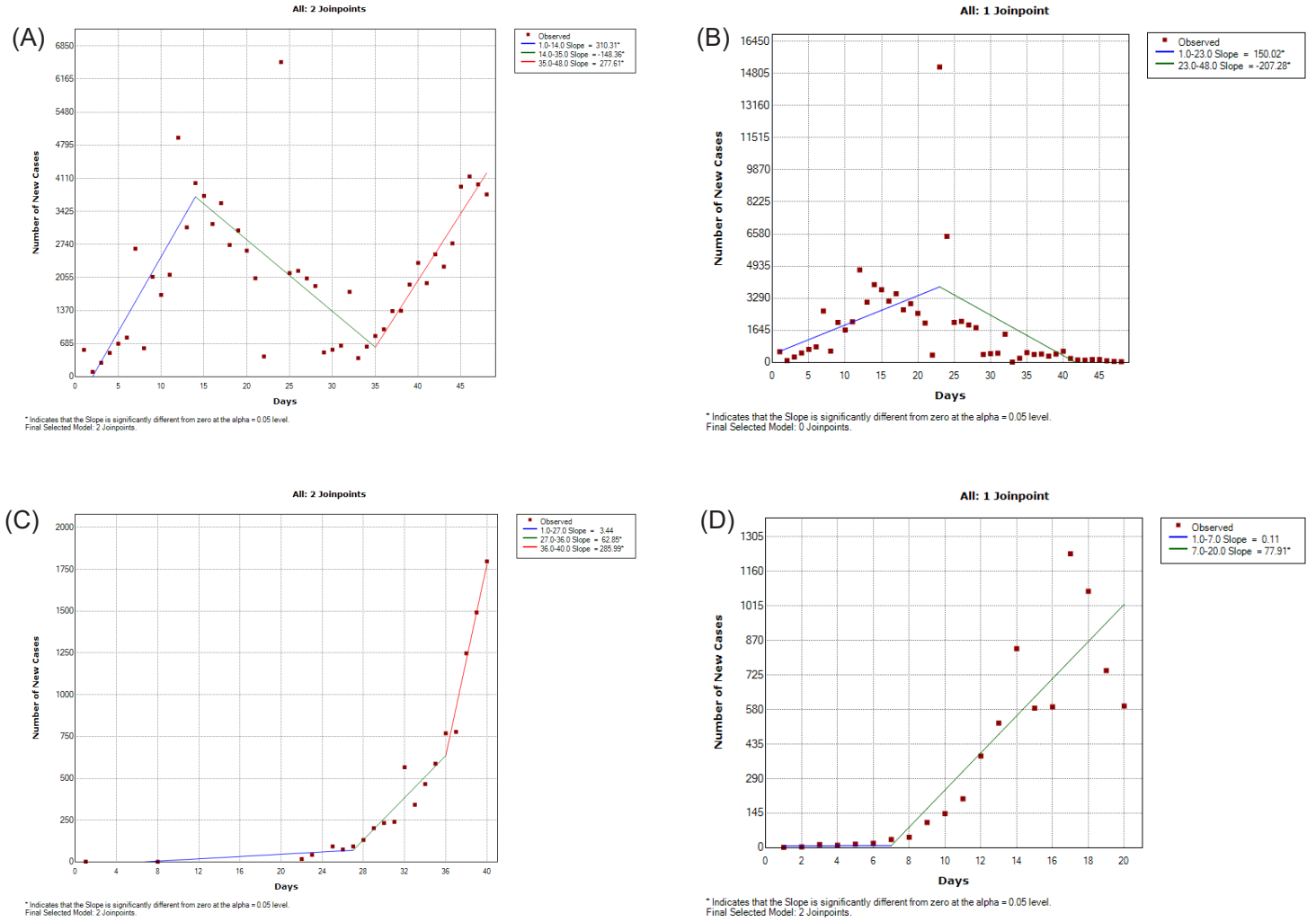

Figure 1. (A) Global, (B) Chinese, (C) Italian and (D) Iranian incidence trend until March 9. 
(197 further cases per day, $P$ value $<0.001$ ) (Figure 2A and $2 \mathrm{~B})$.

Trend of Mortality in China, Italy and the Globe

The change point analysis of mortality was the next step of analysis. The information of mortality in the world estimated the addition of approximately six new deaths per day until day 24 ( $P$ value $<0.001)$. After that, the slope showed a significant descending trend with the estimation of approximately $5(P$ value $=0.002)$ until the 42 nd day of the outbreak. From the 43rd day (the next change point), suddenly a positive significant trend occurred (almost 25 new deaths were added per day $P$ value $<0.001)$. Estimations demonstrated further mortality compared to the first ascending interval (25 added new deaths per day) (Figure 3A). Similar to the global mortality, China had an ascending trend until the $24^{\text {th }}$ day ( 6 new deaths per day, $P$ value $<0.001)$ and following the trend, suddenly there was a significant decline in trend (5 fewer new deaths per day, $P$ value $<0.001)$ emerged and continued until the last day (Figure 3B). Although there were two trend change points in Italy (Figure 3C), there was an ascending trend from the beginning of the outbreak to the last day. In the first 30 days, it was estimated that each day about 1 death occurred more than the previous day $(P$ value $=$ 0.001). After that period, from the 31 st to the $36^{\text {th }}$ day, the estimation increased to almost 8 cases $(P$ value $<0.001)$.

(A)

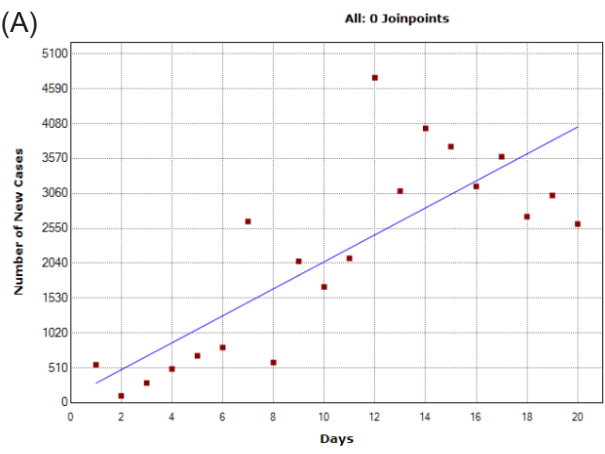

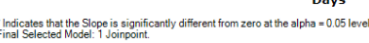

(B)

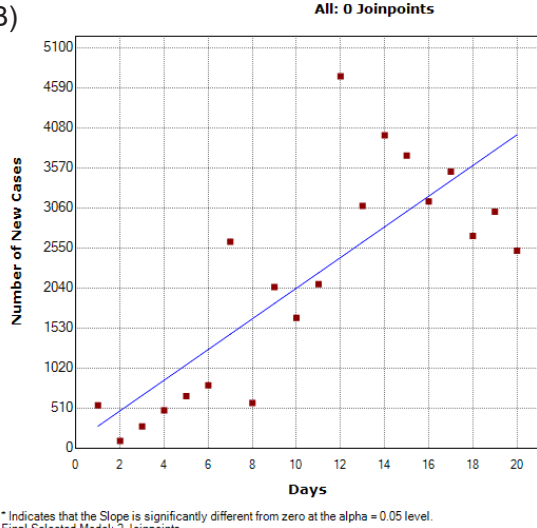

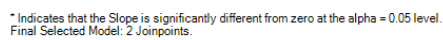

Figure 2. (A) Global and (B) Chinese Incidence Trend in the First 20 Days of Outbreak.

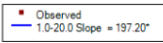

-1.0200 Silooe $=19720^{-0}$ $\mathcal{C}_{1.020 .0 .05 \text { lope }}=195.32^{\circ}$
The results showed a sharp increase in mortality after day 36. We estimated about 40 more new deaths until the last day $(P$ value $<0.001)$.

Comparing Mortality Trend in the First 20 Days in Iran and the Globe

There was a significant increasing trend in the globe $(P$ value $<0.001$ ) (Figure 4 ). Five new cases per day were expected in Iran similar to the global estimate. There was an ascending significant trend, but on the $17^{\text {th }}$ day, there was a change point which showed that the expected further new cases were increased. The results illustrated that until the $17^{\text {th }}$ day, approximately 1 new more death would occur
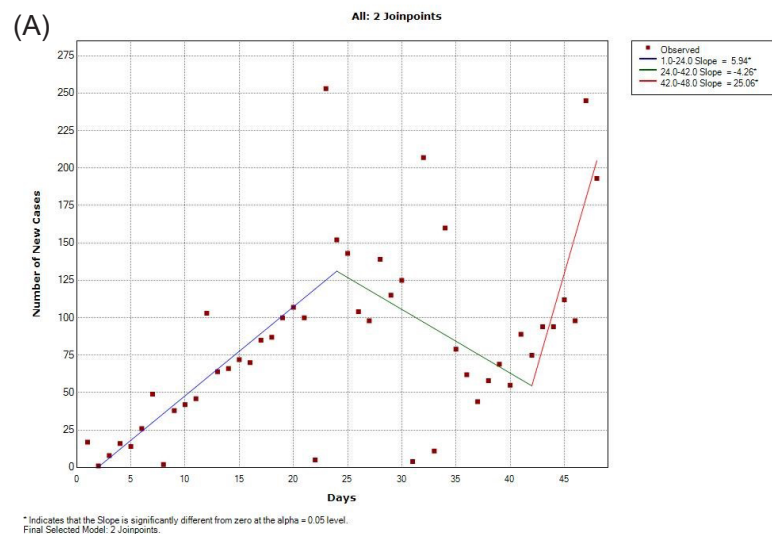

(B)

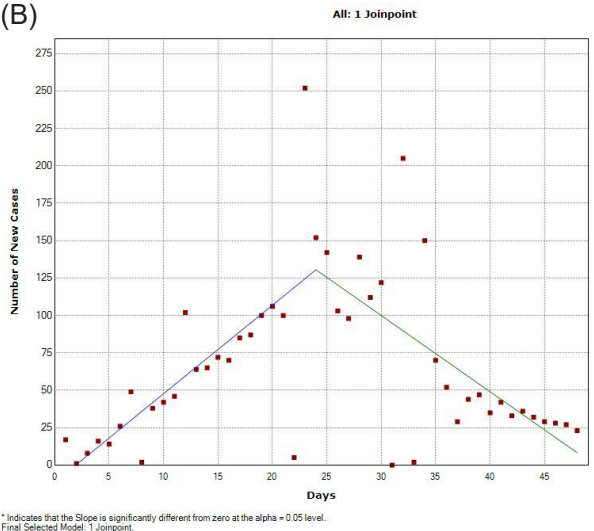

(C)

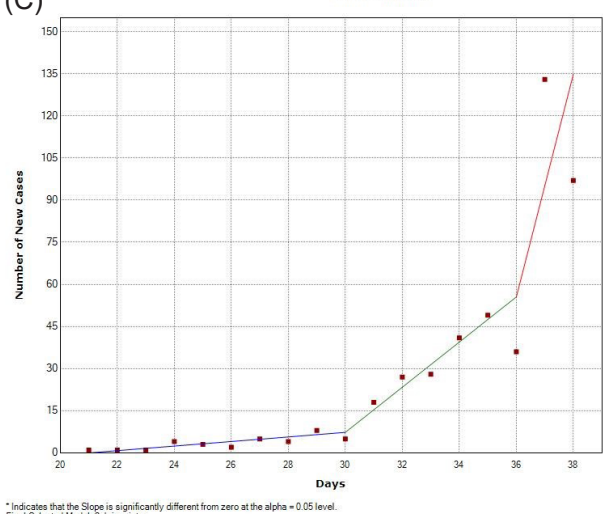




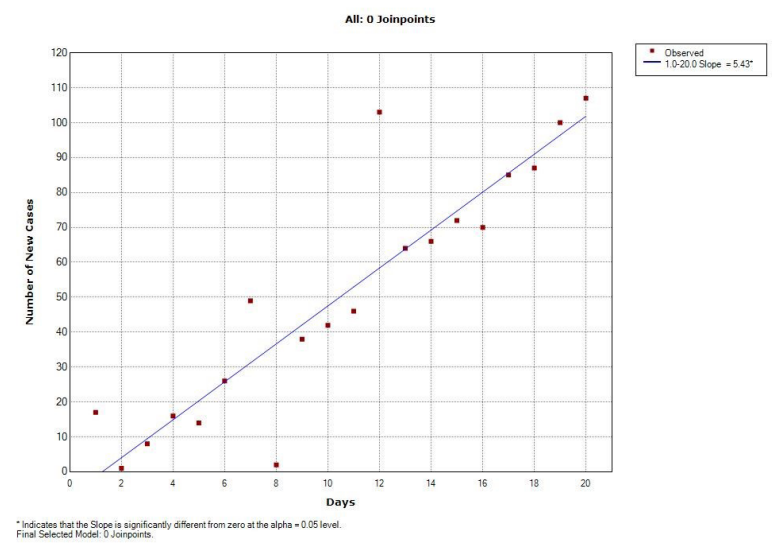

Figure 4. Global Mortality Trend in the First 20 Days of Outbreak.

in the next day, while the estimation for the time after the $17^{\text {th }}$ day was about 12 further new deaths (Figure 5).

The global mortality during the first 20 outbreak days was almost similar to China. Thus, the results of China were not reported.

\section{Discussion}

This study provides an overview of incidence and mortality rate patterns on the global level with special attention to Iran, Italy and China as the countries most involved with COVID-19.

The WHO has published the data since January 22, 2020 and it is updated on a daily basis. We used this data until March 9, almost three months after the first report of the outbreak in China. Finally, on March 11, the WHO announced that COVID-19 can be characterized as 'pandemic'. This announcement shows the importance of the global investigation of incidence and mortality. Nevertheless, we did not find any statistical difference in mortality rates by regions while a significant variety of incidence was found in different regions. These results show that although some risk factors such as regional characteristics could affect incidence, the risk factors associated with mortality are not related to the region, and genetic parameters might have affected mortality.

On the other hand, analyzing the correlation between HDI index and incidence confirms that countries with high development scores would experience a high incidence rate of COVID-19. This finding might be explained by the fact that developed countries have better access to diagnostic methods for rapid diagnosis, registration and reports. For example, as of March 9, there has been no report from countries such as Syria or some poor African countries like Somalia. It confirms that these countries do not have the facilities or even a stable government to check and test patients and report to the WHO. In addition, one cannot overlook the fact that developed countries are more connected to other countries due to greater trade, tourism, etc. These communications may result in easier and faster spread of the virus in these countries, as the virus spread

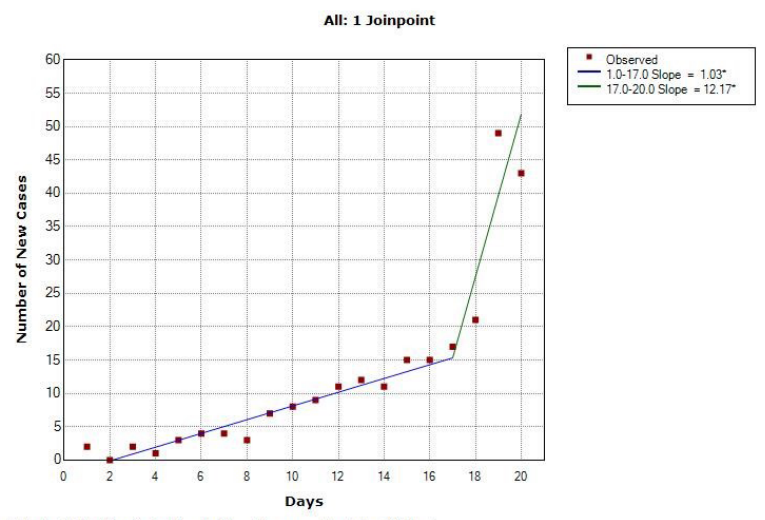

-Indicates that the Slope is significantly different from zero at the alpha $=0.05$ level
Final Selected Model: 1 Noinpoint.

Figure 5. Iranian Mortality Trend until March 9.

rapidly across China during the first days of outbreak, even with quarantine in effect. There was not any significant correlation between HDI and mortality rate, suggesting that developed countries were not safe from mortality and advanced treatments were not effective.

Two other previous versions of the coronavirus that affected the world were the SARS-CoV and the MERSCoV. SARS-CoV was identified in 2003 and first infected humans in the Guangdong province of southern China in 2002. ${ }^{13}$ The MERS-CoV infection was first reported in September 2012 in Saudi Arabia, but an outbreak in Jordan in April 2012 was confirmed retrospectively. ${ }^{14}$ There is a paucity of data on the incidence of SARS and MERS in the literature. It seems that the incidence of these two coronaviruses was not as important as that of COVID-19 because neither of them became pandemic as COVID-19 did.

Following southern China, SARS occurred in Toronto in Canada, the Hong Kong Special Administrative Region of China, Chinese Taipei, Singapore, and Hanoi in Vietnam. The most reported cases of MERS after the Arabian Peninsula were in the Republic of Korea in 2015. Cases were also confirmed in countries throughout Europe, Asia, North Africa, the Middle East, and the United States. ${ }^{6}$

While the incidence of SARS and MERS were lower than COVID-19, the mortality rate of COVID-19 has been considerably lower than them. According to the WHO reports, the mortality rates of SARS-CoV and MERS-CoV were about $9.6 \%$ and $36 \%$, respectively ${ }^{15,16}$ while it is about 3\% For COVID-19.

COVID-19 is pandemic and it seems that the rapid contagious spread of this virus makes it an emergency to study the incidence rates and make comparisons between different regions of the world. Although COVID-19 is more widespread and needs more attention in different regions, there are some studies that have investigated mortality and some risk factors associated with mortality in SARS and MERS in specific countries. ${ }^{14}$ For example, one study investigated if the infection control measures 
during the 2003 SARS outbreak in Toronto were associated with a change in overall population mortality. ${ }^{17}$ In another study from Saudi Arabia, the authors reported the 3- and 30-day survival rates and their risk factors in a large MERS-CoV population. ${ }^{18}$ Some other epidemiological studies have investigated the clinical predictors or risk factors associated with mortality. ${ }^{19,20}$

Due to the rapidly increasing incidence trend of COVID-19, studies are still mostly focused on controlling and prevention issues or virology studies. ${ }^{21-24}$ However, in the current study, using a special statistical method, we focused on incidence and mortality rate trend in the world. Until March 9, Iran and Italy made a dramatically change in the worldwide incidence. We addressed these two countries separately in this research. Also, China, as the origin of COVID-19, was considered separately.

Change point analysis showed an ascending trend in the world and all the mentioned regions except China, which, unlike other regions, has shown success in controlling COVID-19 from day 23. It seems that the regular, timely quarantine program was the key point of this success. After day 23 , according to the results of change point analysis, the daily incidence decreased by 207 cases on average. Italy had the most rapid increase in our comparisons. The entire northern Italy was first placed under quarantine, but this move did not succeed in controlling the spread of the virus, necessitating quarantine in the entire country. Following these measures, the slope of incidence was still ascending. Therefore, the appropriate time for starting quarantine is important for controlling the spread of the virus.

In this regard, Iran did not establish any quarantine. Comparing the first 20 days of outbreak between China, Iran and the world shows that although China could control the infection on the 23rd day (may be due to establishing quarantine), the speed of transfer of the virus was greater in China compared to Iran. This result shows that being aware of the new infection with COVID-19 could facilitate controlling the incidence sooner.

Another interesting finding in our results was the time gap between the jumping point in mortality and incidence rate of the world, which was almost six days. In other words, six days after a rapid rise in the global incidence rate (day 36), we observed a rapid rise in mortality rate (day 42). This may be helpful in knowing the interval from diagnosis to death.

In conclusion, the following points may be important findings of our study. First, the incidence of COVID-19 was different in various regions; however, after March 11 , it turned into a pandemic. The time gap between jumping point in global mortality and incidence rates was almost six days. It means that on average, death occurred six days after the outbreak. This might be helpful in medical emergencies for saving patients and predicting mortality rate on a specific day. On the other hand, China managed to control the increasing outbreak on day 23 . This highlights the importance of quarantine plans in controlling this virus at the right time.

\section{Authors' Contribution}

SC designed the model and the computational framework, analyzed the data, and developed the theoretical part. AP investigated and supervised the findings of this work and directed the project. MV participated in planning the work and wrote the manuscript with supervision of AP and SC.

\section{Conflict of Interest Disclosures}

There is no conflict of interest.

\section{Ethical Statement}

The investigation received no external funding. All the used data in this manuscript was released from $\mathrm{WHO}$ and there is no need to obtain informed consent or ethical considerations.

\section{References}

1. Zhu N, Zhang D, Wang W, Li X, Yang B, Song J, et al. A Novel Coronavirus from Patients with Pneumonia in China, 2019. New Engl J Med. 2020;382(8):727-33. doi: 10.1056/ NEJMoa2001017.

2. WHO. Coronavirus Disease 2019 (COVID-19) Situation report-1.21 January 2020. Available from: https://www.who.int/ docs/default-source/coronaviruse/situation-reports/20200121sitrep-1-2019-ncov.pdf?sfvrsn=20a99c10_4.

3. Chan JF, Lau SK, To KK, Cheng VC, Woo PC, Yuen KY. Middle East respiratory syndrome coronavirus: another zoonotic betacoronavirus causing SARS-like disease. Clin Microbiol Rev. 2015;28(2):465-522. doi: 10.1128/cmr.00102-14.

4. Cheng VC, Chan JF, To KK, Yuen KY. Clinical management and infection control of SARS: lessons learned. Antiviral Res. 2013;100(2):407-19. doi: 10.1016/j.antiviral.2013.08.016.

5. Cheng VCC, Lau SKP, Woo PCY, Yuen KY. Severe acute respiratory syndrome coronavirus as an agent of emerging and reemerging infection. Clin Microbiol Rev. 2007;20(4):660. doi: 10.1128/CMR.00023-07.

6. WHO EMRO. Infectious disease outbreaks reported in the Eastern Mediterranean Region in 2018. 15th of June 2020. Available from: http://www.emro.who.int/pandemic-epidemic-diseases/news/infectious-disease-outbreaks-reported-in-the-eastern-mediterranean-region-in-2018.html.

7. WHO. Coronavirus Disease 2019 (COVID-19) Situation report-51.11 March 2020. Available from: https://www.who.int/ docs/default-source/coronaviruse/situation-reports/20200311sitrep-51-covid-19.pdf?sfvrsn=1 ba62e57_10.

8. WHO. Coronavirus Disease 2019 (COVID-19): situation report-31. Available from: https://www.who.int/docs/defaultsource/coronaviruse/situation-reports/20200220-sitrep-31covid-19.pdf?sfvrsn=dfd11d24_2. 20 February 2020.

9. WHO. Coronavirus Disease 2019 (COVID-19) Situation report-11. Available from: https://www.who.int/docs/defaultsource/coronaviruse/situation-reports/20200131-sitrep-11ncov.pdf?sfvrsn=de7c0f7_4. 31 January 2020.

10. GitHub. Coronavirus package. Available from: https://github. com/RamiKrispin/coronavirus.

11. Stanton EA. The human development index: A history. PERI Working Papers. 2007:85. Available from: https://scholarworks. umass.edu/cgi/viewcontent.cgi?article=1101\&context=peri_ workingpapers.

12. Taylor WA. Change-point analysis: a powerful new tool for detecting changes. Available from: https://pdfs.semanticscholar. org/c723/b683b231b1917804f217d186cfbe5be25079.pdf.

13. Holmes KV. SARS coronavirus: a new challenge for prevention and therapy. J Clin Invest. 2003;111(11):1605-9. doi: 10.1172/ JCl18819. 
14. Zumla A, Hui DS, Perlman S. Middle East respiratory syndrome. The Lancet. 2015;386(9997):995-1007. doi: 10.1016/S01406736(15)60454-8.

15. Christl AD, Mamun RM, Amgad E, Simon C, Maria DVK. Worldwide Reduction in MERS Cases and Deaths since 2016. Emerg Infect Dis. 2019;25(9):1758. doi: 10.3201/ eid2509.190143.

16. WHO. Update 49 - SARS case fatality ratio, incubation period. 2003. Available from: https://www.who.int/csr/sars/ archive/2003_05_07a/en/.

17. Hwang SW, Cheung AM, Moineddin R, Bell CM. Population mortality during the outbreak of Severe Acute Respiratory Syndrome in Toronto. BMC Public Health. 2007;7(1):93. doi: 10.1186/1471-2458-7-93.

18. Ahmed AE. The predictors of 3- and 30-day mortality in 660 MERS-CoV patients BMC Infect Dis. 2017;17(1):615. doi: 10.1186/s12879-017-2712-2.

19. Alfaraj SH, Al-Tawfiq JA, Assiri AY, Alzahrani NA, Alanazi AA, Memish ZA. Clinical predictors of mortality of Middle East Respiratory Syndrome Coronavirus (MERS-CoV) infection: A cohort study. Travel Med Infect Dis. 2019;29:48-50. doi: 10.1016/j.tmaid.2019.03.004.
20. Adegboye OA, Gayawan E, Hanna F. Spatial modelling of contribution of individual level risk factors for mortality from Middle East respiratory syndrome coronavirus in the Arabian Peninsula. PLoS One. 2017;12(7):e0181215. doi: 10.1371/ journal.pone.0181215.

21. Cheng VCC, Wong S-C, Chen JHK, Yip CCY, Chuang VWM, Tsang OTY, et al. Escalating infection control response to the rapidly evolving epidemiology of the Coronavirus disease 2019 (COVID-19) due to SARS-CoV-2 in Hong Kong. Infect Cont Hosp Epidemiol. 2020:41(5):493-8. doi: 10.1017/ ice.2020.58.

22. Lipsitch M, Swerdlow DL, Finelli L. Defining the Epidemiology of Covid-19 - Studies Needed. N Engl J Med. 2020;382(13):1194-6. doi: 10.1056/NEJMp2002125.

23. Kannan S, Shaik Syed Ali P, Sheeza A, Hemalatha K. COVID-19 (Novel Coronavirus 2019) - recent trends. Eur Rev Med Pharmacol Sci. 2020;24(4):2006-11. doi: 10.26355/ eurrev_202002_20378.

24. She J, Jiang J, Ye L, Hu L, Bai C, Song Y. 2019 novel coronavirus of pneumonia in Wuhan, China: emerging attack and management strategies. Clin Transl Med. 2020;9(1):19. doi: 10.1186/s40169-020-00271-z. 